Supplement of The Cryosphere, 16, 297-314, 2022 https://doi.org/10.5194/tc-16-297-2022-supplement (c) Author(s) 2022. CC BY 4.0 License.

(c) (1)

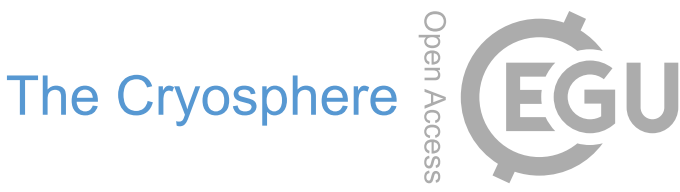

Supplement of

\title{
Dam type and lake location characterize ice-marginal lake area change in Alaska and NW Canada between 1984 and 2019
}

\section{Brianna Rick et al.}

Correspondence to: Brianna Rick (brianna.rick@ colostate.edu)

The copyright of individual parts of the supplement might differ from the article licence. 


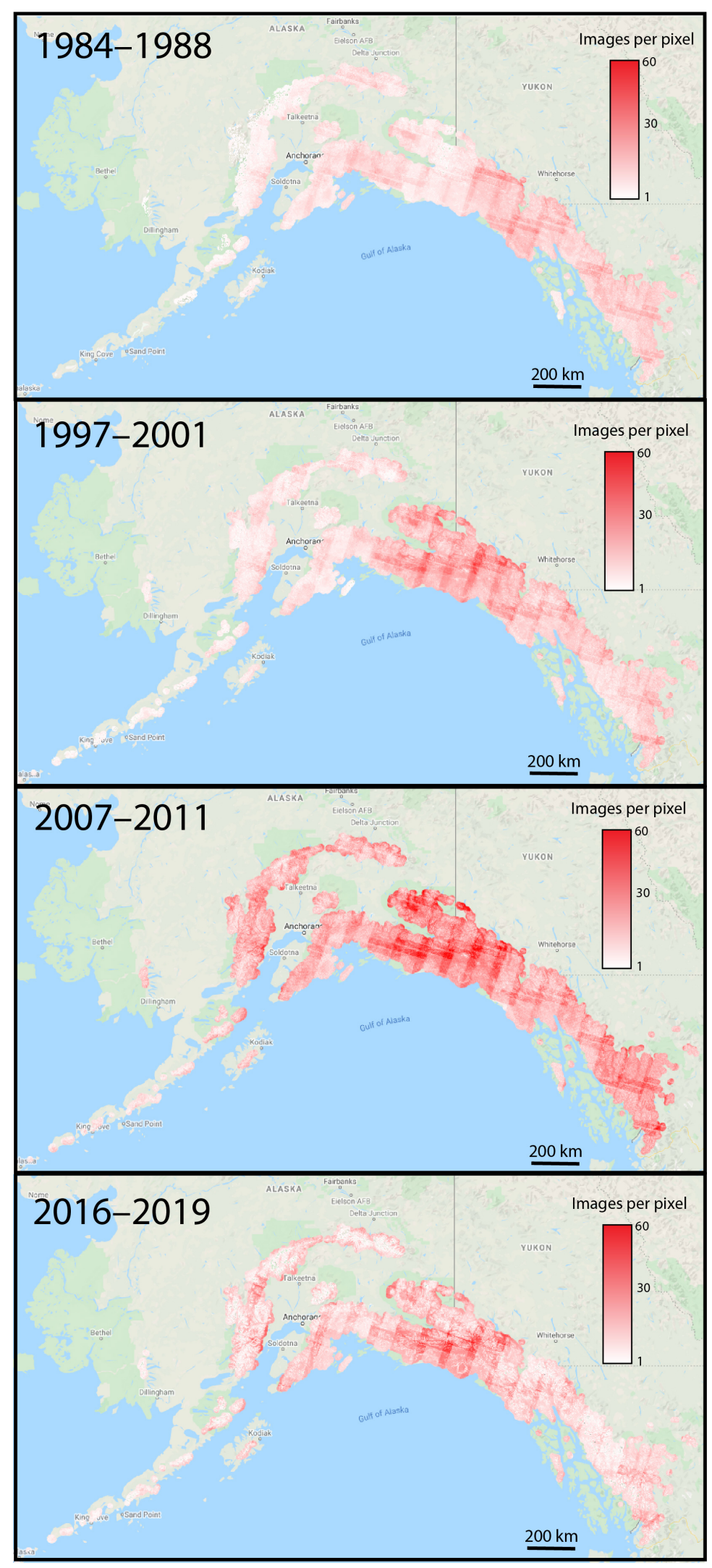

Fig. S1. Images per pixel per time period for each mosaic (median of each pixel value) used in analysis. Maps created in (C) Google Earth Engine (Gorelick et al., 2017). 
a) "Lakes" from classification

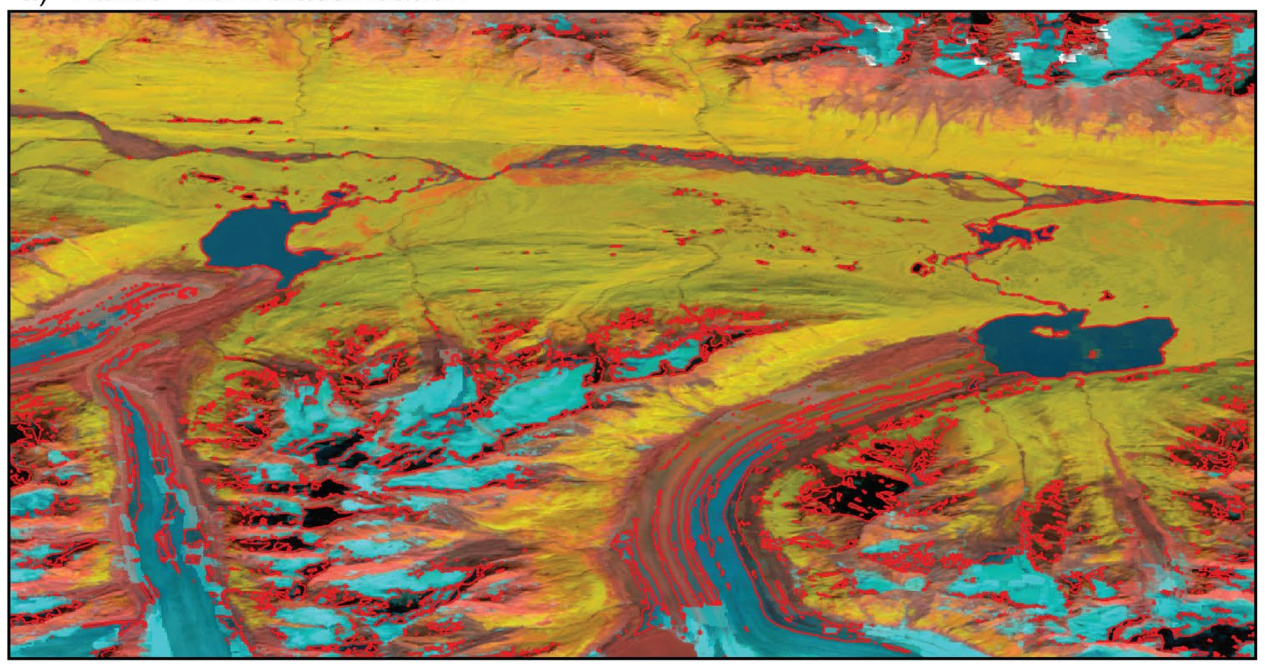

b) "Lakes" after thresholding

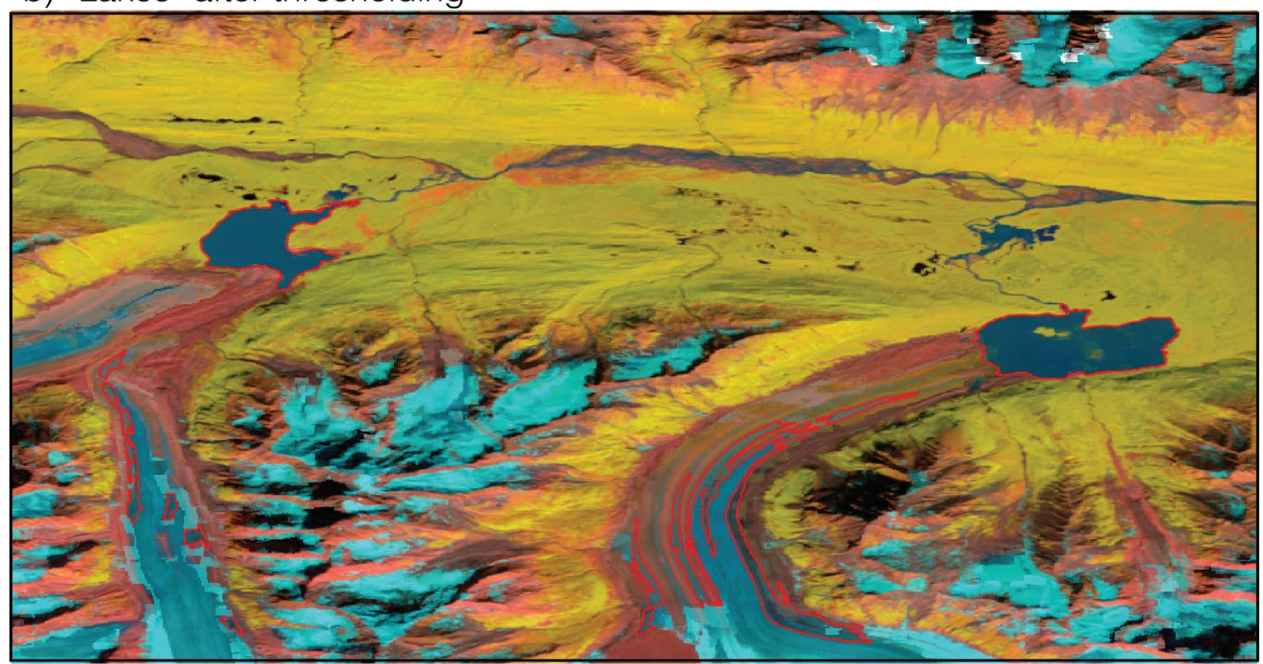

c) Final lake outlines after manual cleaning

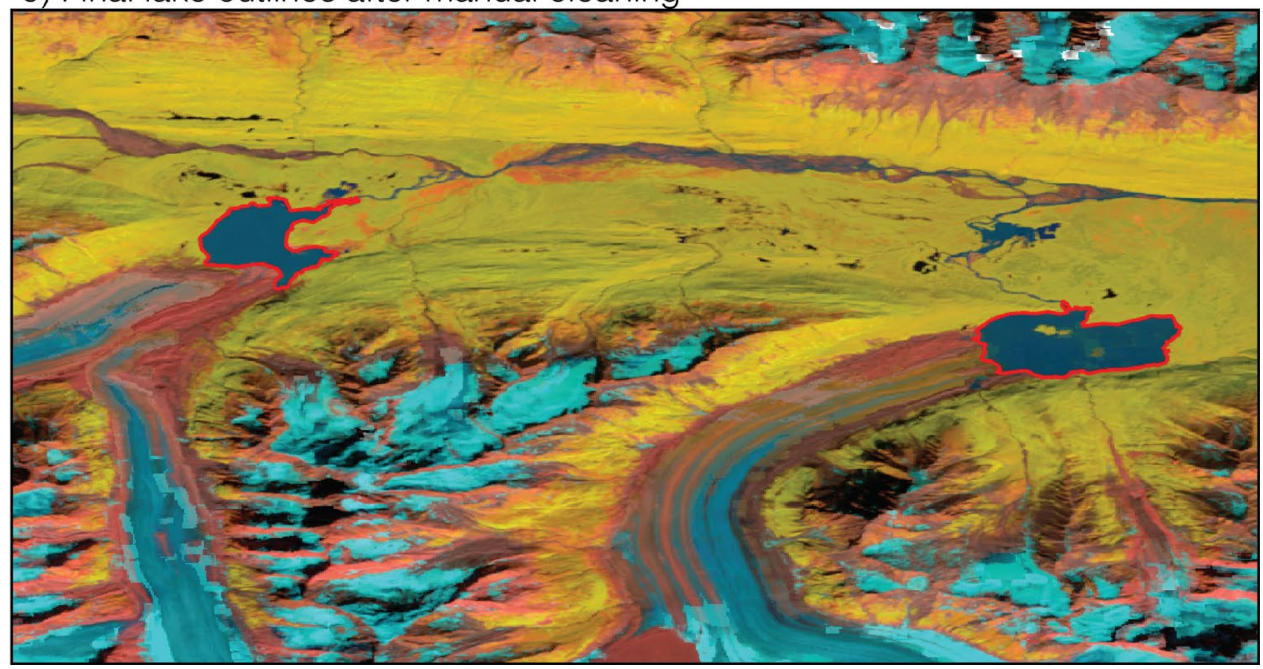

Fig. S2. Example of lake polygons after supervised classification (a), after applying slope, area, distance, and length:area ratio thresholds (b), and after manual verification. Polygon outlines are in red. False color images using Landsat bands for shortwave infrared (SWIR), near infrared (NIR), and red. 


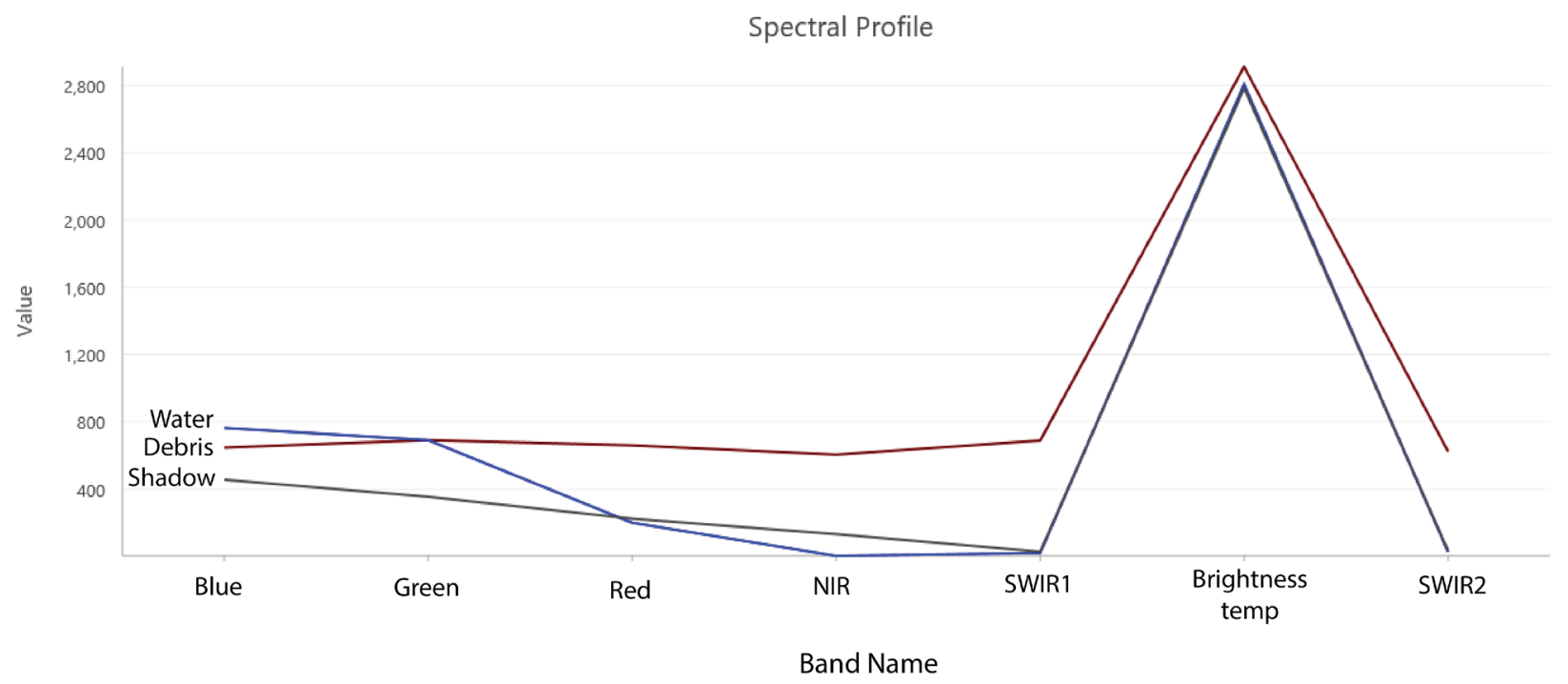

Fig. S3. Spectral comparison of water, mountain shadow, and a debris band.

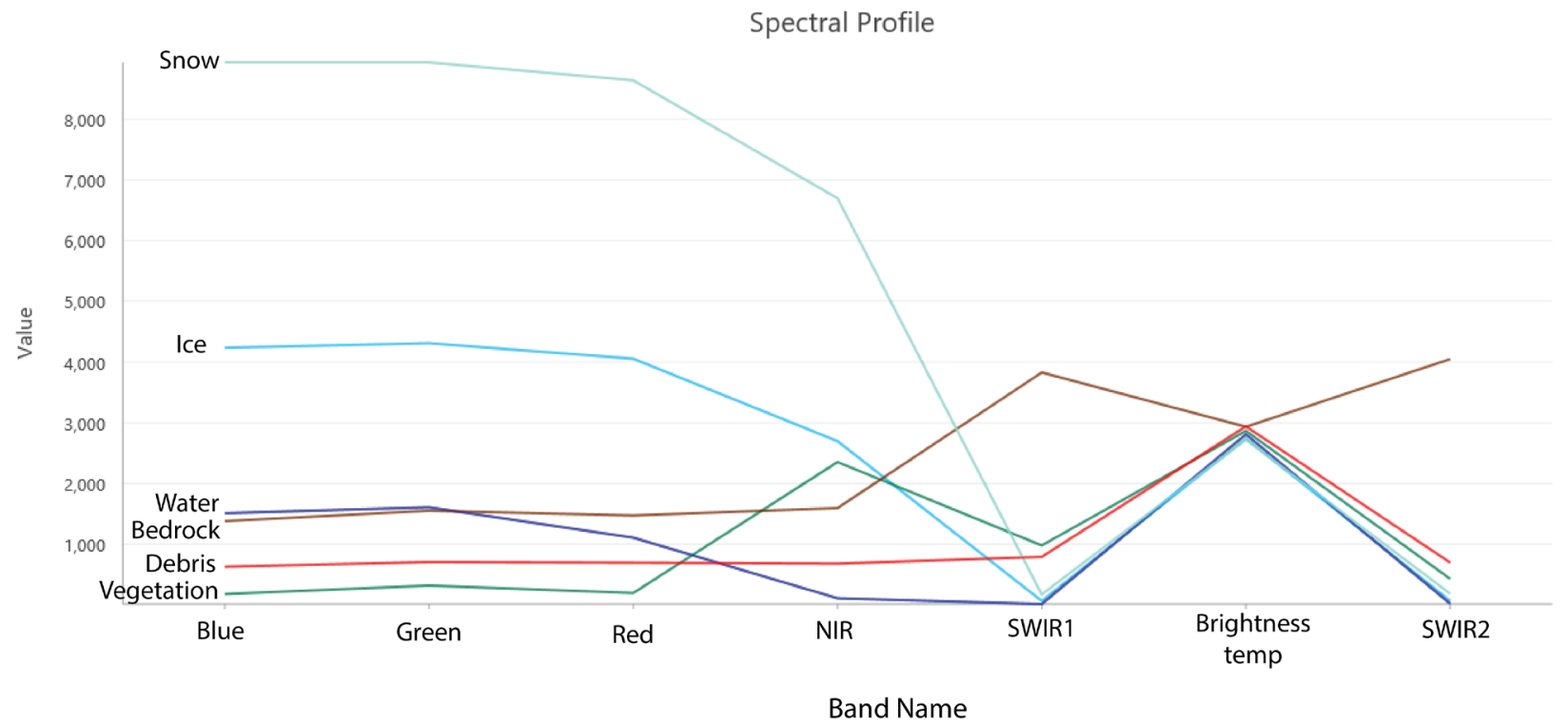

Fig. S4. Example spectral profiles for each landcover type (snow, ice, water, bedrock, debris, and vegetation) used in supervised classification. 


\begin{tabular}{|c|c|c|c|}
\hline $\begin{array}{l}\begin{array}{l}\text { Lake dam type } \\
\text { O Bedrock } \\
\bigcirc \text { Supraglacial } \\
\text { O Ice } \\
\text { O Moraine }\end{array} \\
\text { All dam types }\end{array}$ & All lakes $\longrightarrow$ Lakes with & $\begin{array}{l}\mathrm{n}_{\mathrm{all}}=791 \\
\mathrm{n}_{\text {detect }}=344\end{array}$ & $\begin{array}{l}M_{\text {all }}=0.00 \\
M_{\text {detect }}=0.05\end{array}$ \\
\hline Supraglacial & & $\begin{array}{l}\mathrm{n}_{\mathrm{all}}=238 \\
\mathrm{n}_{\text {detect }}=93\end{array}$ & $\begin{array}{l}M_{\text {all }}=0.00 \\
M_{\text {detect }}=0.03\end{array}$ \\
\hline Moraine & & $\begin{array}{l}\mathrm{n}_{\mathrm{all}}=268 \\
\mathrm{n}_{\text {detect }}=164\end{array}$ & $\begin{array}{l}M_{\text {all }}=0.04 \\
M_{\text {detect }}=0.13\end{array}$ \\
\hline Ice & & $\begin{array}{l}\mathrm{n}_{\text {all }}=91 \\
\mathrm{n}_{\text {detect }}=41\end{array}$ & $\begin{array}{l}M_{\text {all }}=0.00 \\
M_{\text {detect }}=-0.06\end{array}$ \\
\hline Bedrock & & $\begin{array}{l}\mathrm{n}_{\text {all }}=194 \\
\mathrm{n}_{\text {detect }}=46\end{array}$ & $\begin{array}{l}M_{\text {all }}=0.00 \\
M_{\text {detect }}=0.02\end{array}$ \\
\hline & i & & \\
\hline-10 & $\begin{array}{c}0 \\
\text { Area change }\left(\mathrm{km}^{2}\right)\end{array}$ & 10 & 20 \\
\hline
\end{tabular}

Fig. S5. Smoothed density distribution (normalized to 1 for each dam type) of absolute lake area change for all lakes (dark curves) and lakes with detectable change (light curves) for each dam type, with number of lakes (n) and median lake area change (M).

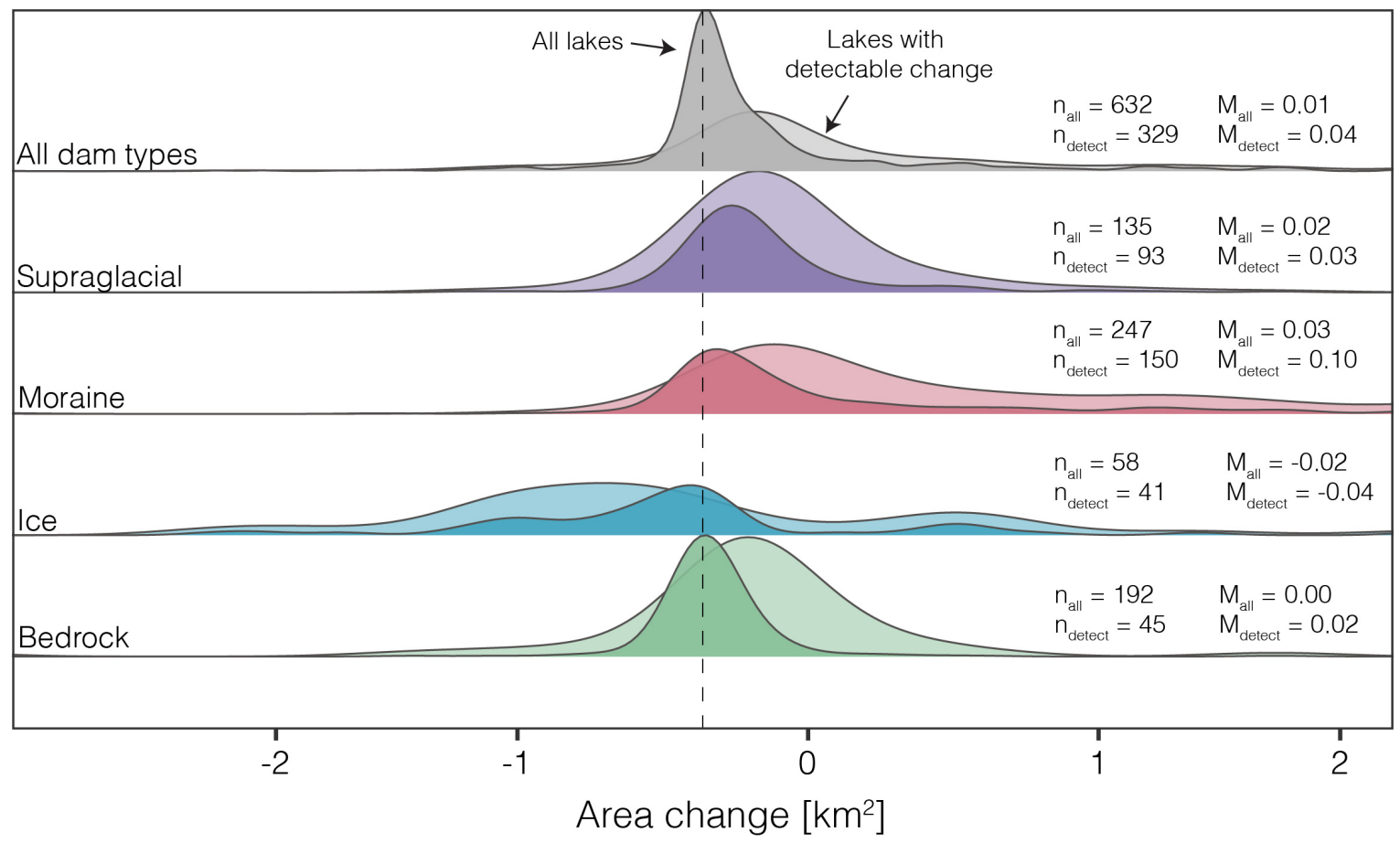

Fig. S6. Smoothed density distribution (normalized to 1 for each dam type) of absolute lake area change for all lakes with an area less than $10 \mathrm{~km}^{2}$ in 2016-2019 (dark curves) and lakes with detectable change (light curves) for each dam type, with number of lakes (n) and median lake area change (M). Note that the $\mathrm{x}$-axis has been limited to -2 and $2 \mathrm{~km}^{2}$. 


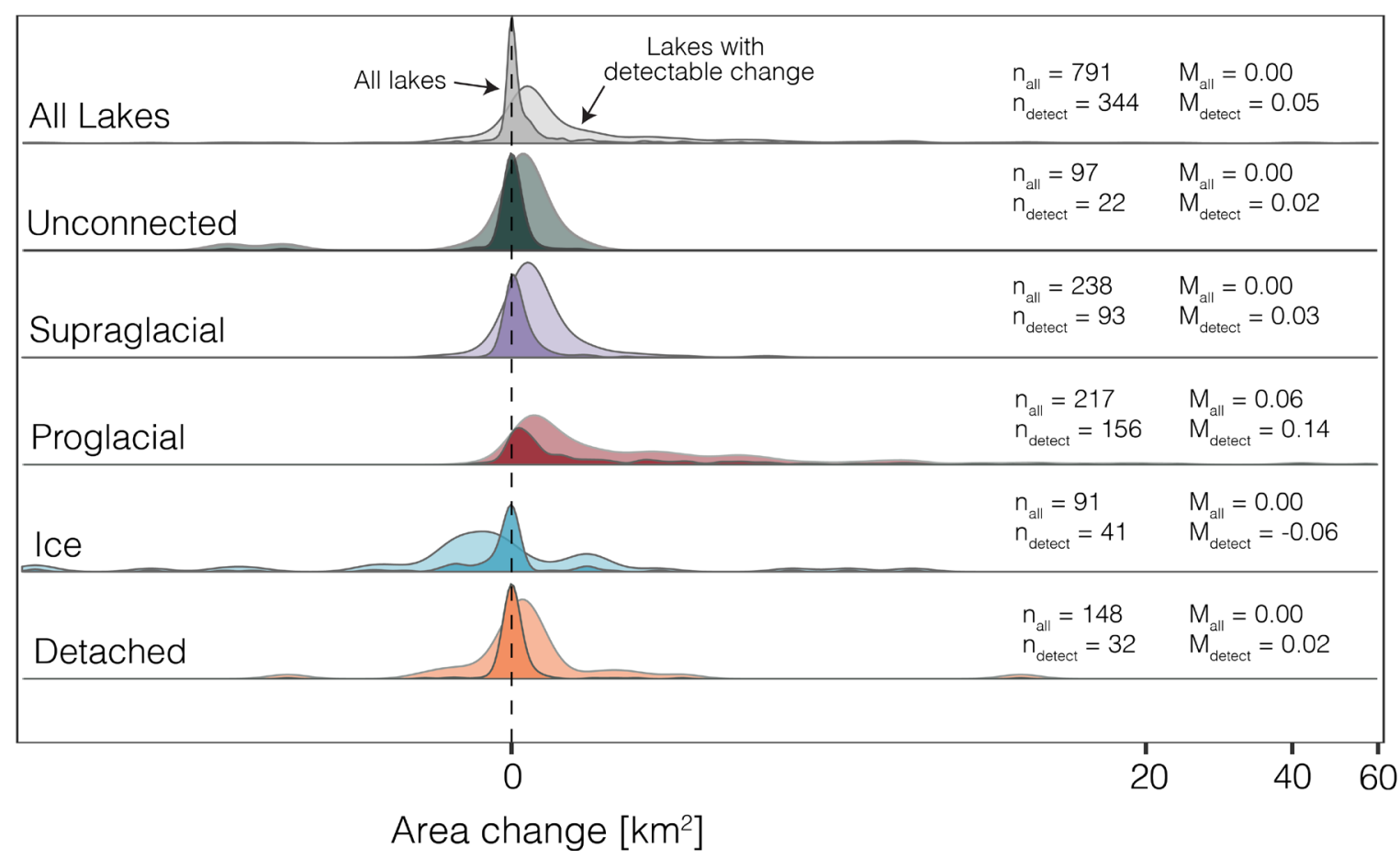

Fig. S7. Distribution of lake area change $\left(\mathrm{km}^{2}\right)$ for all lakes (dark curves) and lakes with detectable change (light curves) for each topological position, with number of lakes (n) and median lake area change (M).

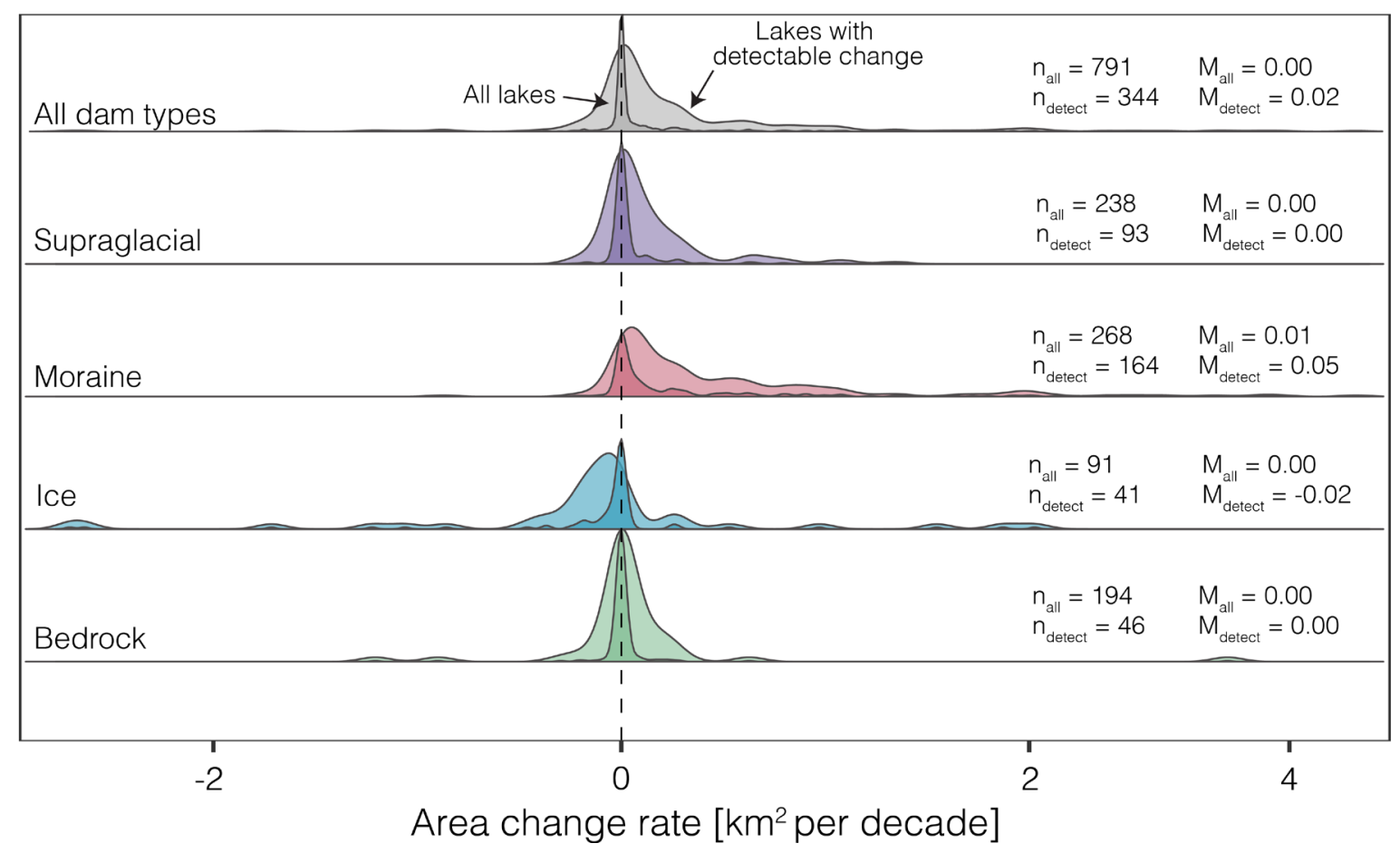

Fig. S8: Distribution of lake area change rate $\left(\mathrm{km}^{2}\right.$ per decade) for all lakes (dark curves) and lakes with detectable change (light curves) for each dam type, with number of lakes (n) and median lake area change (M). 


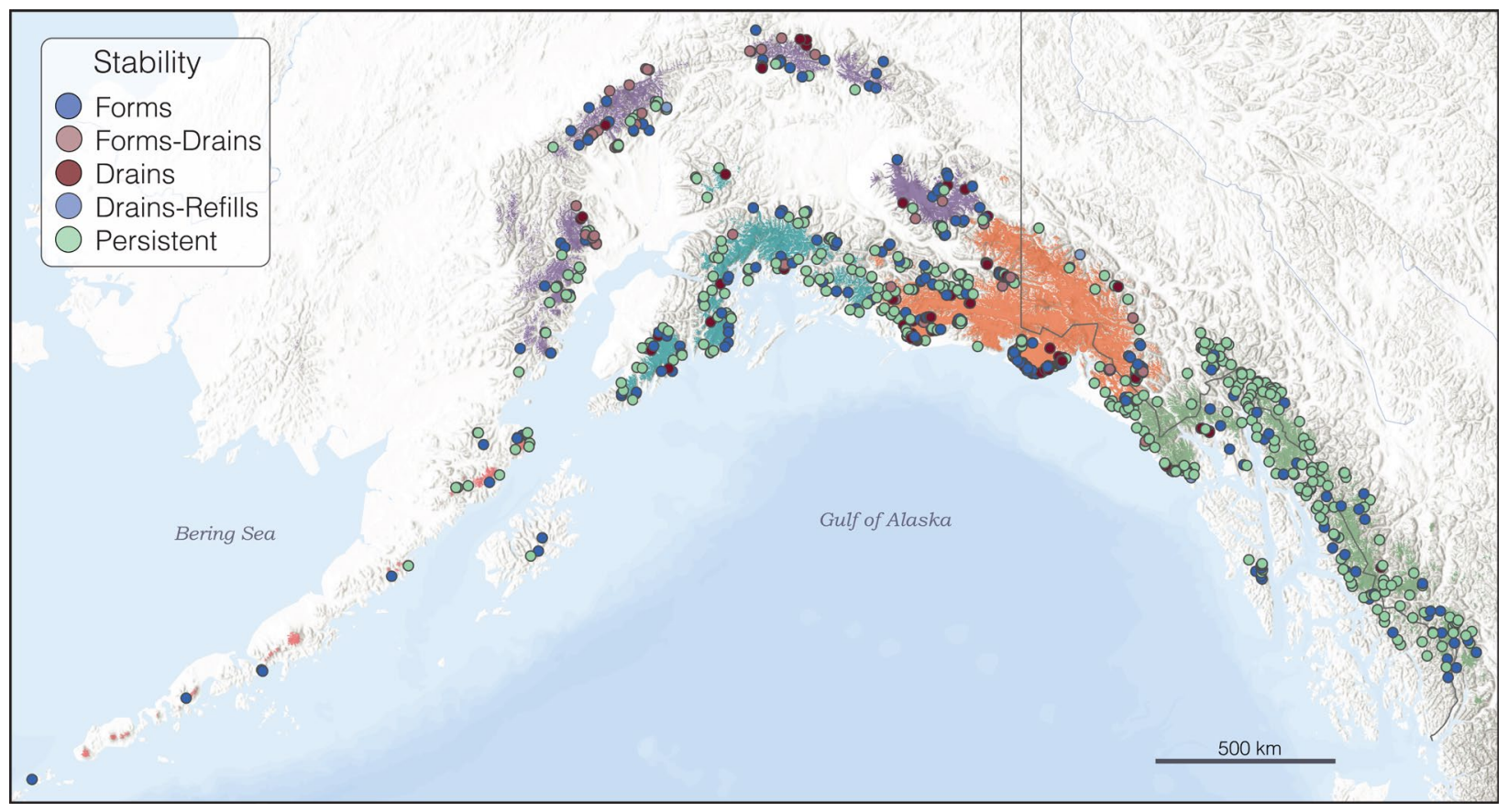

Fig. S9. Lake stability distribution across Alaska. Each dot represents an individual lake. Colored areas refer to the RGI subregions (see Fig. 1) (basemap provided by ESRI, 2021). 


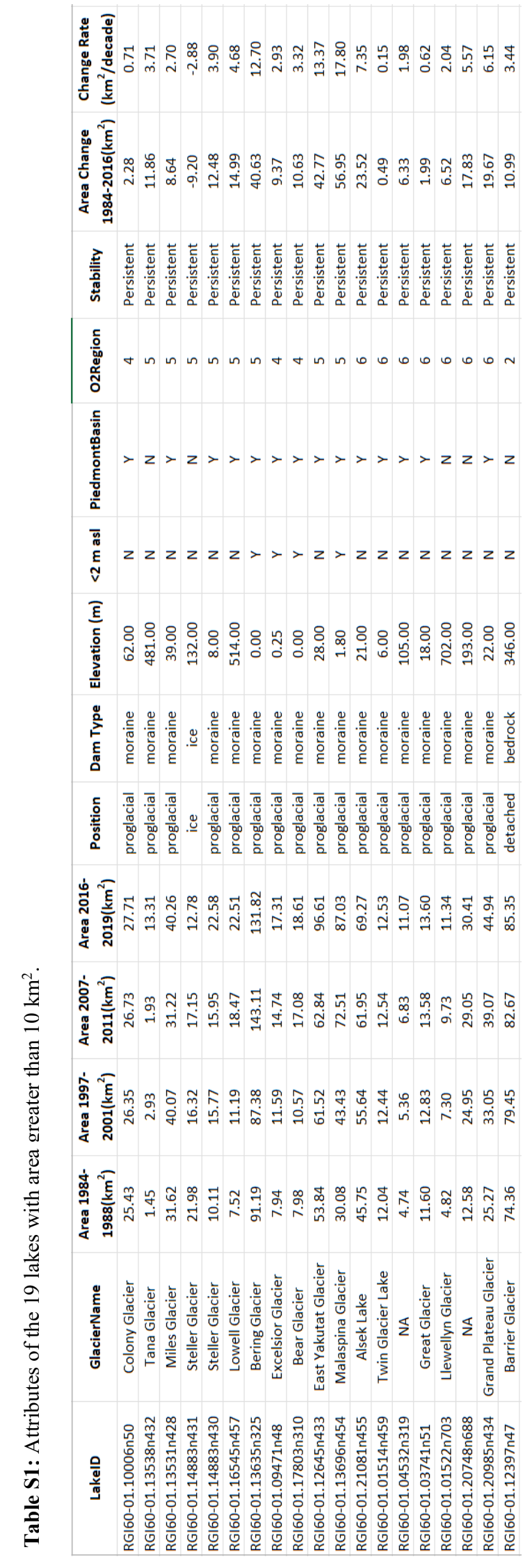

